\title{
Recent Advancement of the Molecular Diagnosis in Pediatric Brain Tumor
}

\author{
Jeong-Mo Bae, M.D., Ph.D., Jae-Kyung Won, M.D., Ph.D., ${ }^{1}$ Sung-Hye Park, M.D., Ph.D., ${ }^{1,2}$ \\ Department of Pathology, Seoul National University Hospital, Seoul National University College of Medicine, Seoul, Korea \\ Department of Neuroscience Institute, ${ }^{2}$ Seoul National University College of Medicine, Seoul, Korea
}

Recent discoveries of brain tumor-related genes and fast advances in genomic testing technologies have led to the era of molecular diagnosis of brain tumor. Molecular profiling of brain tumor became the significant step in the diagnosis, the prediction of prognosis and the treatment of brain tumor. Because traditional molecular testing methods have limitations in time and cost for multiple gene tests, next-generation sequencing technologies are rapidly introduced into clinical practice. Targeted sequencing panels using these technologies have been developed for brain tumors. In this article, focused on pediatric brain tumor, key discoveries of brain tumor-related genes are reviewed and cancer panels used in the molecular profiling of brain tumor are discussed.

Key Words : Brain neoplasms - Pediatrics - Molecular diagnostics · High-throughput nucleotide sequencing · Next generation sequencing.

\section{INTRODUCTION}

Since the end of the Human Genome Project, a number of genomic studies of human disease such as The Cancer Genome Atlas (TCGA) and International Cancer Genome Consortium have been activated ${ }^{25}$. Such large scale genome studies were enabled by the development of massively parallel sequencing technology, also known as next-generation sequencing (NGS), which can rapidly generate high-throughput data with low per-base $\operatorname{cost}^{5,40)}$.

In addition, targeted anti-cancer therapy has been highlighted with the discovery of cancer driver genes ${ }^{32,67)}$. Such clinical needs, in turn, prompted the development of sequencing technologies and cancer genome studies. TCGA, the large scale cancer genome study consortium, started its three-year pilot project in 2006, especially about glioblastoma and now completed the characterization of 33 cancer types including 10 rare cancers ${ }^{7}$.

The acceleration of genomic studies in the field of brain tumor led to the discovery of key genes in brain tumor development, such as isocitrate dehydrogenase (IDH), H3F3A, and alpha thalassemia/mental retardation syndrome X-linked $(A T R X)^{52,64)}$. In addition, these genes have been found to be deeply involved in the diagnosis and prognosis of brain tumor.

Brain tumor is the most common type of solid cancer in chil-

- Received : March 13, 2018 •Revised : April 4, 2018 •Accepted : April 7, 2018

- Address for reprints : Sung-Hye Park, M.D., Ph.D.

Departments of Pathology, Neuroscience Institute, Seoul National University College of Medicine, 101 Daehak-ro, Jongno-gu, Seoul 03080, Korea

Tel : +82-2-2072-3090, Fax : +82-2-765-5600, E-mail : shparknp@snu.ac.kr

\section{Jae-Kyung Won, M.D., Ph.D.}

Department of Pathology, Seoul National University Hospital, Seoul National University College of Medicine, 101 Daehak-ro, Jongno-gu, Seoul 03080, Korea Tel : +82-2-2072-4895, Fax : +82-2-743-5530, E-mail : jkwon@snuh.org

This is an Open Access article distributed under the terms of the Creative Commons Attribution Non-Commercial License (http://creativecommons.org/licenses/by-nc/4.0) which permits unrestricted non-commercial use, distribution, and reproduction in any medium, provided the original work is properly cited. 
dren. Over the past decade, molecular research on brain tumors has made unprecedented progress in pediatric brain tumors. Unique genomic and epigenomic alterations are continuously discovered according to the patients' age, tumor grade, and histologic differences of brain tumors in large-scale global collaborative studies. In addition, the therapeutic paradigm is changing as targeted therapies are developed to correct the genetic abnormalities, prompting a new sub-classification of brain tumors. In 2016, the new World Health Organization (WHO) classification of central nervous system (CNS) tumors incorporated the genetic abnormalities into the classification and diagnosis of the tumor ${ }^{38}$. Therefore, some tumors must undergo molecular testing, which is essential for accurate diagnosis. Sometimes multiple tests are required for each patient, so multiplex panel tests using NGS method have begun to be used in clinical settings to meet the reasonable turnaround time and the price.

In this article, the important genetic abnormalities involved in brain tumors, especially in pediatric brain tumors, are reviewed and the existing brain tumor panels are analyzed to suggest the optimal design of the pediatric brain tumor panel.

\section{GENETIC ABNORMALITIES IN PEDIATRIC GLIOMAS}

Gliomas are the most common CNS tumors in children and adolescents ${ }^{81}$. Children's gliomas are mostly low-grade, classified as grade 1 or grade 2 according to the WHO classification of CNS tumors and appear to be slowly growing lesions. Low grade glioma (LGG) in children is fundamentally different from those of adult which are characterized by IDH mutation and have generally good prognosis. Gliomas are currently not fully cured, despite efforts to utilize all currently available treatment. Therefore, the purpose of the treatment of LGGs, which is pursued by neurosurgeons, pediatric oncologists and radiation therapists, is to improve the quality of life of patients and prevent long-term sequelae.

Among gliomas, the newly included tumors in the WHO classification revised in 2016 is the diffuse midline glioma, H3 K27Mmutant, a broad-spectrum central glioma within the astrocytictumor category ${ }^{38)}$. RELA fusion-positive ependymoma was classified as a new subtype of supratentorial ependymoma.

\section{Low grade gliomas including other astrocytic tumors}

In the newly revised WHO classification in 2016, pilocytic astrocytoma (PA), pleomorphic xanthoastrocytoma (PXA), subependymal giant cell astrocytomas are belonging to the "other astrocytic tumor". About 50\% of optic pathway PA and about $4 \%$ of cerebellar PA occurs in families with mutations in the neurofibromatosis type 1 (NF1) gene and the rest occurs sporadically ${ }^{24)}$. In these gliomas, the most common somatic point mutation is BRAF V600E mutation causing BRAF activation, which is also observed in 33\% of ganglioglioma, $70 \%$ of PXA, and approximately $15 \%$ of pediatric $\mathrm{LGG}^{4,60)}$. The $70 \%$ of PA showed one copy gain of BRAF gene, by the fusion between BRAF gene and KIAA1549 gene located on chromosome $7 \mathrm{q} 34^{58,80)}$. As a result of overactivation of $M E K$ and $E R K$ genes in the down-stream of $B R A F$ signaling pathway, gliomagenesis is known to occur ${ }^{31}$. BRAF gene duplication is known to occur in more than $80 \%$ of PA of posterior fossa and $22 \%$ of the pilomyxoid astrocytoma ${ }^{16)}$. Other BRAF fusion partners (FAM131B, SRGAP3, MACF1, RNF130, CLCN6, MRKN1, and GNAII) result in equally strong $B R A F$ activation through the loss of the N-terminal of autoregulatory domain ${ }^{73)}$. However, the effect of specific BRAF abnormalities on the prognosis is unclear $^{81)}$. In one study of 146 childhood PAs, BRAF-KIAA1549 fusion was associated with a good prognosis while other studies do not show any association with prognosis ${ }^{74}$.

The mutations of other genes, including FGFR1, MYB, MYBL1, and $A T R X$, have been identified through whole exome sequencing (WES) of these gliomas ${ }^{55}$.

\section{Diffuse midline glioma, H3 K27M-mutant (WHO grade IV)}

Gliomas with histone H3 K27M mutation, formerly called infiltrating brainstem or pontine glioma have been named as "diffuse midline glioma, H3 K27M-mutation" in the revised WHO classification ${ }^{30,33)}$. These tumors are classified as astrocytic and oligodendroglial tumor category and are classified as WHO grade IV glioma of the pediatric population, which occur in the midline of CNS, such as thalamus, pons and spinal cord. It has been shown that high grade gliomas in children have genetic abnormalities and gene expressions different from adults and their prognosis is different ${ }^{29,68)}$. In 2014, Histone gene mutation was found to be a driver mutation through WES $^{33,71,76)}$. This tumor usually differentiates into astrocytes 
and is morphologically similar to WHO grade IV human astrocytoma. In addition to $\mathrm{H} 3 \mathrm{~K} 27 \mathrm{M}$ mutation, the mutation of TP53 (50\%), PPM1D (15\%), ACVR1 (20\%), PDGFRA (10\%), and $S M A R C A 4 / B$ (<5\% of cases) can be present ${ }^{44,68)}$.

It is known that tumors with this mutation are worse than those without the K27M-mutation among the same grade glioma in the same region. Two-year survival rate is generally less than $10 \%$ when treated with current therapies ${ }^{64,76)}$.

\section{Ependymomas}

It is known that the genetic aberration of ependymoma varies depending on the tumor site of the CNS and the biology of the tumor follows genetic characteristics ${ }^{50,77)}$. Although the morphology of the lesion may be identical, it can be divided into three groups according to the location of the tumor because the gene abnormality is different ${ }^{50)}$.

About $70 \%$ of cases of supratentorial ependymomas are characterized by RELA-C11orf95 fusion and 30\% by YAP1 gene fusion $^{43,77)}$. It is known that the LAMA2 overexpression group show worse prognosis than NELL2 overexpression group among the cases of posterior fossa ependymomas, ${ }^{1,46)}$. In the spinal cord, familial ependymomas are known to associate with NF1 gene mutation, while the other spinal cord ependymomas do not show any specific mutation but it is known that they show three types of copy number variation ${ }^{50)}$.

\section{Ependymoma, RELA fusion-positive}

This C11orf95-RELA fusion ependymoma is a new genetic subtype of the supratentorial ependymoma which has been newly included in the 2016 WHO classification. The C11orf95RELA gene fusion, which is one of the genetic features of the ependymomas above the tent, is associated with the activation of $N F-\kappa B$ pathway, ${ }^{1,51)}$. The partner gene can be a gene other than C11orf95. The grade of this tumor follows a pathologic grade that is evaluated according to existing morphologic features, but the prognosis is worse in the case of RELA fusion than YAP fusion ${ }^{43,51)}$.

\section{NEURONAL AND MIXED NEURONAL-GLIAL TUMORS}

Thirteen tumors belong to mixed neuronal-glial tumors, including dysembryoplastic neuroepithelial tumor, ganglion cell tumor, papillary glioneuronal tumor, rosette-forming glioneuronal tumor, central neurocytoma, extraventricular neurocytoma, cerebellar liponeurocytoma and paraganglioma.

Diffuse leptomeningeal glioneuronal tumor was newly included in the revised 2016 WHO classification.

\section{Gangliocytoma and ganglioglioma}

It is known that approximately $20-43 \%$ of neuroepithelial neoplams and ganglioglioma show BRAF V600E mutation and the frequency of this mutation increases with the degree of malignancy ${ }^{31,51)}$. BRAF V600E mutation is related to the use of a targeted therapeutic agent for this mutation, such as vemurafenib. The BRAF V600E mutation also has been reported to be associated with the worse prognosis of ganglioglioma ${ }^{39,81)}$.

\section{Diffuse leptomeningeal glioneuronal tumor (Inter- national Classification of Diseases for Oncology [ICDO] code and WHO grade not yet assigned)}

There are few reported cases of diffuse leptomeningeal glioneuronal tumors (DLGNT). WHO grade has not yet been established in this tumor ${ }^{20)}$.

A recent report showed the presence of $B R A F$ duplication in about $44 \%$ and $B R A F$ V600E mutation in about $11 \%{ }^{15)}$. Other aberrations in MAPK/ERK pathways including RAF1, FGFR1, $N F 1$, and $M Y B$ or $M Y B L 1$ were also reported ${ }^{81)}$. Low grade nature of DLGNT was reported, but cases having nuclear atypia, high Ki-67 index and glomerular vascular proliferation may show bad prognosis ${ }^{11}$.

\section{CNS EMBRYONAL TUMORS}

The most significant change in the revised 2016 WHO classification is the CNS embryonal tumor, previously referred to as the CNS primitive neuroectodermal tumor (CNS PNET). The reason for the change in the name of the tumor is to prevent confusion with the extracranial PNETs, such as Ewing sarcoma. Among CNS embryonal tumors, medulloblastoma (MB) is classified according to the combination of tumor genetics and morphological subtype ${ }^{38)}$. Embryonal tumor with multilayered rosettes (ETMR; chromosome 19 microRNA cluster [C19MC] altered, and not otherwise specified [NOS]) is newly added to the 2016 WHO classification, which is characterized by gene amplification at the site of the microRNA clusters on chromo- 
some $19^{38,69)}$.

However, if morphologically CNS PNET, described above, is not genetically clear, it is classified as "CNS embryonal tumor, NOS”. ETMR can strongly express Lin28 or show the amplification of C19MC locus on 19q13.42 chromosome region or both $^{69,70)}$.

\section{Medulloblastomas}

$\mathrm{MB}$ is the most common embyonal tumor of the CNS and is common in children. Most occur in the cerebellum but exceptionally, WNT activated tumors can occur in the dorsal brainstem $^{22)}$. In accordance with the known genetic abnormalities and morphologic features, it is classified by two classification systems, i.e., genetically determined and morphologically determined classification ${ }^{38)}$.

Genetic MB classification is composed of WNT-activated, Sonic Hedgehog (SHH)-activated, group 3 and group 4. CTNNB1 mutation and monosomy 6 are the characteristics of WNT subtype ${ }^{18)}$. The germline or somatic mutation of the TP53 gene is observed in $\mathrm{SH} H$-activated MB, but not observed in the WNT-activated MB or group 3 and group $4 \mathrm{MBs}^{69)}$. The SHH MB with TP53 gene mutation is known to have a poor $\operatorname{prognosis}^{82)}$.

In contrast, group 3 and group 4 MBs are immunohistochemically and molecular-genetically overlapped and they show copy number variations in variable chromosomal loci ${ }^{53)}$. In many hospitals, these two groups are classified as non-WNT/non-SHH groups because group 3 and group 4 cannot be easily categorized by conventional laboratory tests. Tumors with either MYC or N$M Y C N$ gene amplification or anaplastic/large cell type have poorprognosis $^{82)}$. Generally, group 3 has the worst prognosis ${ }^{19,53)}$. If there are cerebrospinal metastases, the prognosis is poor and the recurrence is common ${ }^{2,53)}$. MB with extensive nodularity usually has a good prognosis ${ }^{9)}$. If genetic testing is not possible or the results are ambiguous, it can be diagnosed as MB, NOS.

In order to genetically classify MBs, originally it is necessary to examine the mutation of several genes and chromosome copy number variation. Currently, immunohistochemistry can be used to classify $\mathrm{MB}^{72)}$. However, it is not easy to interpret the immunoreactivity and match with genetic subgroup.

Recently, according to Cavalli et al. ${ }^{9)}$, the genetic groups of MB can be further subdivided. That is, it is subdivided into WNT $\alpha$ to $\beta, S H H \alpha$ to $\delta$, group $3 \alpha$ to $\gamma$, and group $4 \alpha$ to $\gamma$, which better reflect the prognosis and clinical characteristics".

\section{Embryonal tumor with multilayered rosettes, C19MC altered, and NOS, WHO grade IV}

This tumor is one of the malignant CNS tumors. It is composed of multiple layers of rosettes and broad neuropil, and also has genetic characteristics of C19MC in chromosomal band 19q13.42 amplification or fusion with Tweety family member 1 (TTYH1) gene ${ }^{35,47)}$. This can be confirmed by fluorescence in situ hybridization (FISH). These tumors are very rare and can occur in the cerebrum, brain stem, and cerebellum.

If the tumor is morphologically compatible but has not undergone genetic tests or has no abnormality of this gene by the molecular test, it is diagnosed as an "embryonal tumor with multilayered rosettes, NOS”. This tumor is a very rapidly growing WHO grade IV tumor with a poor prognosis, and the average survival time with the current treatment is 12 months (reported up to 24-36 months), and the relationship between the gene alteration and the prognosis should be studied ${ }^{37)}$.

\section{CNS embryonal tumor, NOS}

Most of the tumors diagnosed as "CNS-PNET" in the past are now diagnosed as "CNS embryonal tumor, NOS". These tumors are very rare CNS neuroepithelial tumor with poor differentiation, and the specific morphological features or classifiable genetic abnormalities of these tumors have not yet been revealed $^{26,38)}$. Most of these tumors express Lin 28 immunohistochemically ${ }^{69,70)}$. The prognosis of this tumor is very poor (WHO grade IV), and worse than that of the $\mathrm{MB}^{3)}$.

\section{Atypical teratoid/rhabdoid tumor (AT/RT) $)^{23)}$}

AT/RT are characterized by the mutation of SMARCB1 (95\%) or SMARCA4 (about 2\%) genes ${ }^{23}$. When the mutation of those genes is not examined or this mutation is not found in spite of compatible histology, it is diagnosed as "CNS embryonal tumor with rhabdoid features".

A rare case of a malignant neoplasm characterized by atypical morphology and rhabdoid features with acquisition of the secondary SMARCB1 mutations in PXA and GG was reported ${ }^{65)}$.

\section{GERM CELL TUMORS}

\section{Germinoma}

CNS Germ cell tumor (GCT) has been known to have a common chromosomal abnormality $12 \mathrm{p}$ redundancy, $\mathrm{i}(12 \mathrm{p})$, which 
was found in studies of malignant testicular tumors ${ }^{14)}$. The most common cytogenetic abnormality in extragonadal germinomas is the $12 p$ overlap $^{61}$. However, specific genes on $\mathrm{i}(12 \mathrm{p})$ associated with the development of GCT are not known.

Cytogenetic abnormalities as driver mutations in childhood GCT include the loss of $1 \mathrm{p}$ and $6 \mathrm{q}$, the changes in sex chromosomes, and $12 \mathrm{p}$ abnormalities with some gains ${ }^{62}$. The most common chromosomal imbalance is an increase in the X chromosome, as well as an increase in $1 p, 8 p$, and 12q, and a loss in $13 q$ and $18 \mathrm{q}^{62}$. The most frequent gene abnormality in CNS GCTs is XXY, similar to Klinefelter syndrome which tends to develop GCTs in the intracranium ${ }^{49)}$.

In the intracranial pure germinomas, mutations of KIT/ RAS gene were frequently detected, and mutations in the KIT gene exones 11, 13, and 17 as well as KIT amplification were found in $23-25 \%$ of intracranial GCTs ${ }^{63)}$. It is thought to contribute to the development of GCTs. MYC or MYCN amplification can be observed in a small number of GCTs ${ }^{21)}$.

\section{Non-germinomatous germ cell tumor}

In the yolk sac tumor (YST), chromosome 1p36 gain, 6q loss and chromosome 1 and chromosome 20 abnormalities have been reported ${ }^{41)}$. In addition, $\mathrm{i}(12 \mathrm{p})$, which is characteristic of other malignant GCTs of testis and ovary, can be detected ${ }^{12,54)}$. Embryonal carcinoma and choriocarcinoma show similar cytogenetic abnormalities, $\mathrm{i}(12 \mathrm{p})^{64,65)}$.

Immature teratomas are usually diploid, whereas YST can be diploid, tetraploid or aneuploid ${ }^{66}$. Chromosomal abnormalities include gain of chromosomes $\mathrm{X}, 1,3,8,12$, and 14, i(12p) and loss of $\mathrm{X}$ and $\mathrm{Y}$. There may be loss of $1 \mathrm{q}$ and rearrangement of $3 \mathrm{q}$ and $6 \mathrm{q}^{13,57,78)}$.

\section{CURRENT STATUS OF TARGETED NEXT- GENERATION SEQUENCING IN BRAIN TUMORS}

There has been a great progress in the understanding of molecular characteristics of brain tumors by genome-wide study, such as WES and whole genome sequencing $(\mathrm{WGS})^{10,48}$. However, targeted NGS panel composed of limited number of genes is required for the routine clinical practice of brain tumor diagnosis and treatment. For the clinical NGS test of brain tumors, we should consider the spectrum of sequencing panel (pancancer panel or organ-specific panel), target enrichment meth- od (hybrid capture or amplicon sequencing), type of tissues (fresh frozen [FF] or formalin-fixed paraffin-embedded [FFPE] tissues) and gene contents ${ }^{27}$. The summary of targeted NGS panels used for brain tumors in recent publications is shown in Table 1 . There are three types of panel : pan-cancer, brain tumor-specific and glioma-specific panel.

Pan-cancer panels and organ-specific panels have pros and cons. Pan-cancer panels are usually composed of more than 300 genes of major oncogenes, tumor suppressor genes and druggable genes frequently altered in various type of cancers. Because of large target region, pan-cancer panels show better performance in copy number alterations (CNA). However, pan-cancer panels usually require more time and cost. Moreover, genes solely mutated in certain type of cancer with rare frequency, such as HIST1H3B or HIST1H3C are not covered by pan-cancer panels. Organ-specific panels consist of lower number of genes than pan-cancer panel, so we can reduce the time and cost for the NGS test. In addition, organ-specific panel covers cancer type-specific genes with rare mutation rate. However, organ-specific panel have limitations in the clinical trial enroll and CNA analysis.

Because the target region of NGS panel is smaller than $1 \%$ of human genome, we should enrich the region of interest in the genome. There are two types of target enrichment method, which are hybrid capture and amplicon method. Hybrid capture method uses DNA or RNA baits complementary to target sequences. The baits are hybridized to target sequences, and collected by magnetic beads. Amplicon sequencing method enriches target sequences by PCR amplification. Hybrid capture method is suitable for NGS panels with more than 50 genes as well as comprehensive genomic analysis including single nucleotide variation (SNV), indel, CNA and structural variation. However, hybrid capture method takes longer hands-on time and turn-around time, and usually requires more than 200 ng of genomic DNA. Amplicon sequencing method has easier workflow, short turnaround time and requires small amount of genomic DNA (more than $20 \mathrm{ng}$ ). However, amplicon sequencing is usually used for NGS panels composed of less than 50 genes, and has a limit to CNA analysis.

FFPE tissue is widely used in the histological diagnosis due to the preservation of morphology, fast tissue preparation, and low cost for storage. However, FFPE tissue has several issues in molecular testing, such as the fragmentation of DNA, crosslinking, and cytidine deamination. For those reasons, DNA extract- 
Table 1. Summary of targeted next-generation sequencing panel used for brain tumor in recently published studies

\begin{tabular}{|c|c|c|c|c|c|c|c|}
\hline Study & $\begin{array}{l}\text { Number of } \\
\text { tested genes }\end{array}$ & $\begin{array}{l}\text { Number of } \\
\text { patients }\end{array}$ & $\begin{array}{l}\text { Sample } \\
\text { type }\end{array}$ & $\begin{array}{l}\text { Tumor type used } \\
\text { in study }\end{array}$ & $\begin{array}{c}\text { Target } \\
\text { enrichment method }\end{array}$ & $\begin{array}{l}\text { Spectrum } \\
\text { of panel }\end{array}$ & $\begin{array}{c}\text { Name of } \\
\text { panel }\end{array}$ \\
\hline $\begin{array}{l}\text { Blumenthal } \\
\text { et al. }(2016)^{6)}\end{array}$ & 236,315 & 43 & FFPE & Glioma & Hybrid capture & Pan-cancer & FoundationOne \\
\hline $\begin{array}{l}\text { Dubbink } \\
\text { et al. }(2016)^{17)}\end{array}$ & 12 & 139 & FFPE & Glioma & Amplicon & Glioma-specific & \\
\hline $\begin{array}{l}\text { Nikiforova } \\
\text { et al. }(2016)^{45)}\end{array}$ & 30 & 54 & FF, FFPE & $\begin{array}{l}\text { Glioma and } \\
\text { non-glioma }\end{array}$ & Amplicon & $\begin{array}{l}\text { Glioma and } \\
\text { non-glioma }\end{array}$ & GlioSeq \\
\hline $\begin{array}{l}\text { Sahm } \\
\text { et al. }(2016)^{59)}\end{array}$ & 130 & 150 & FFPE & $\begin{array}{l}\text { Glioma and } \\
\text { non-glioma }\end{array}$ & Hybrid capture & $\begin{array}{l}\text { Glioma and } \\
\text { non-glioma }\end{array}$ & \\
\hline $\begin{array}{l}\text { Carter } \\
\text { et al. }(2017)^{8)}\end{array}$ & $25,151,99,131$ & 50 & FFPE & Glioma & Hybrid capture & Pan-cancer & $\begin{array}{l}\text { Comprehensive } \\
\text { cancer gene set }\end{array}$ \\
\hline $\begin{array}{l}\text { Johnson } \\
\text { et al. }(2017)^{28)}\end{array}$ & 315 & 282 & FFPE & Glioma & Hybrid capture & Pan-cancer & FoundationOne \\
\hline $\begin{array}{l}\text { Kline } \\
\text { et al. }(2017)^{36)}\end{array}$ & 510 & 31 & FFPE & $\begin{array}{l}\text { Glioma and } \\
\text { non-glioma }\end{array}$ & Hybrid capture & Pan-cancer & $\begin{array}{l}\text { UCSF500 Cancer } \\
\text { Gene Panel }\end{array}$ \\
\hline $\begin{array}{l}\text { Movassaghi } \\
\text { et al. }(2017)^{42)}\end{array}$ & 315 & 71 & FFPE & Glioma & Hybrid capture & Pan-cancer & FoundationOne \\
\hline $\begin{array}{l}\text { Ramkissoon } \\
\text { et al. }(2017)^{56)}\end{array}$ & 300 & 203 & FFPE & $\begin{array}{l}\text { Glioma and } \\
\text { non-glioma }\end{array}$ & Hybrid capture & Pan-cancer & OncoPanel \\
\hline $\begin{array}{l}\text { Zacher } \\
\text { et al. }(2017)^{79)}\end{array}$ & 20 & 121 & FF, FFPE & Glioma & Amplicon & Glioma-specific & \\
\hline
\end{tabular}

FFPE : formalin-fixed paraffin-embedded, FF : fresh frozen

ed from FF is preferred in NGS test. However, several commercially available DNA extraction kit for FFPE yield high quality of DNA from FFPE tissues ${ }^{34)}$. So, both of FF and FFPE tissues can be used in clinical NGS test. When the test was performed with FFPE tissues, $\mathrm{C}$ to $\mathrm{T}$ transition with low variant allele frequency could be false-positive call caused by cytidine deamination. Enzymatic removal of deaminated cytosine by UDP glucuronyl transferase can reduce that error ${ }^{75)}$.

Selection of gene contents for brain tumor panel is based on the classification of brain tumors and corresponding oncogenic pathways. For the diagnosis and classification of gliomas, IDH1, IDH2, ATRX, TP53, CIC, FUBP1, BRAF genes and telomerase reverse transcriptase (TERT) promoter are usually included. For the detection of 1p/19q co-deletion in oligodendroglioma, additional genomic regions which exist in $1 p$ or $19 q$ can be included in the panel. To diagnose diffuse midline glioma, H3F3A, HIST1H3B, and HIST1H3C should be tested. For the classification of MB, APC, CTNNB1, TP53, PTCH1, SMO, SUFU, KDM6A, MYC, MYCN genes and TERT promoter can be used. For the diagnosis of AT/RT, SMARCB1 (INI1) and SMARCA4 (BRG1) can be included. For the therapeutic intent, druggable or potentially druggable target such as HER2, $A L K$, MET, ROS1, KIT, PDGFRA, FGFR1, FGFR3, BRAF can be included in NGS panel.

For now, targeted NGS panel for brain tumors has several limitations. First, reliable detection of copy number alteration is limited due to uneven target coverage, the absence of matched normal data, or the lack of coverage uniformity ${ }^{34)}$. Second, nucleotide sequences with high GC content such as TERT promoter usually show lower depth of coverage ${ }^{17)}$. Third, exact classification of MB and ependymoma based on NGS panel test is limited because of the classification of those tumors are mainly based on transcriptome and methylome analysis ${ }^{9,50)}$.

\section{CONCLUSION}

The molecular abnormalities of pediatric brain tumors and current status of targeted brain cancer panels were reviewed. Due to the completion of the human genome project and the development of gene abnormality testing techniques, the revolution of genomic tests for human diseases are actively under- 
way. Even if morphologically tumors are belonging to the same group, it is found that the prognosis and response to the treatment depend on the gene abnormality. Therefore, pathologic diagnosis has been transformed into the integrated diagnosis reflecting the gene abnormality in the revised 2016 WHO classification of CNS tumors. Brain cancer panel using targeted sequencing will be helpful to such integrated diagnosis and target therapies to cure diseases.

\section{CONFLICTS OF INTEREST}

No potential conflict of interest relevant to this article was reported.

\section{INFORMED CONSENT}

This type of study does not require informed consent.

\section{- Acknowledgements}

This study was supported by the grant of the Korea Health Technology R \& D Project through the Korea Health Industry Development Institute (KHIDI), funded by the Ministry of Health \& Welfare (grant number : HI14C1277) and the National Research Foundation of Korea (NRF) grants, funded by the Ministry of Science and ICT (2015M3A9A7067220), Republic of Korea.

\section{References}

1. Araki A, Chocholous M, Gojo J, Dorfer C, Czech T, Heinzl H, et al. : Chromosome 1q gain and tenascin-C expression are candidate markers to define different risk groups in pediatric posterior fossa ependymoma. Acta Neuropathol Commun $4: 88,2016$

2. Bai RY, Staedtke V, Rudin CM, Bunz F, Riggins GJ : Effective treatment of diverse medulloblastoma models with mebendazole and its impact on tumor angiogenesis. Neuro Oncol 17 : 545-554, 2015

3. Bavle AA, Lin FY, Parsons DW : Applications of genomic sequencing in pediatric CNS tumors. Oncology (Williston Park) 30 : 411-423, 2016

4. Behling F, Barrantes-Freer A, Skardelly M, Nieser M, Christians A, Stockhammer $F$, et al. : Frequency of BRAF V600E mutations in 969 central nervous system neoplasms. Diagn Pathol 11 : 55, 2016

5. Bentley DR, Balasubramanian S, Swerdlow HP, Smith GP, Milton J, Brown $C G$, et al. : Accurate whole human genome sequencing using reversible terminator chemistry. Nature $456:$ 53-59, 2008

6. Blumenthal DT, Dvir A, Lossos A, Tzuk-Shina T, Lior T, Limon D, et al. : Clinical utility and treatment outcome of comprehensive genomic profiling in high grade glioma patients. J Neurooncol 130 : 211-219, 2016

7. Cancer Genome Atlas Research Network : Comprehensive genomic characterization defines human glioblastoma genes and core pathways. Nature 455 : 1061-1068, 2008

8. Carter JH, McNulty SN, Cimino PJ, Cottrell CE, Heusel JW, Vigh-Conrad $\mathrm{KA}$, et al. : Targeted next-generation sequencing in molecular subtyping of lower-grade diffuse gliomas: application of the World Health Organization's 2016 revised criteria for Central Nervous System Tumors. J Mol Diagn 19 : 328-337, 2017

9. Cavalli FMG, Remke M, Rampasek L, Peacock J, Shih DJH, Luu B, et al. : Intertumoral heterogeneity within medulloblastoma subgroups. Cancer Cell 31 : 737-754.e6, 2017

10. Ceccarelli M, Barthel FP, Malta TM, Sabedot TS, Salama SR, Murray BA, et al. : Molecular profiling reveals biologically discrete subsets and pathways of progression in diffuse glioma. Cell $164:$ 550-563, 2016

11. Cho HJ, Myung JK, Kim H, Park CK, Kim SK, Chung CK, et al. : Primary diffuse leptomeningeal glioneuronal tumors. Brain Tumor Pathol 32 : 49-55, 2015

12. Cornejo KM, Cheng L, Church A, Wang M, Jiang Z : Chromosome 12p abnormalities and IMP3 expression in prepubertal pure testicular teratomas. Hum Pathol 49 : 54-60, 2016

13. Dal Cin P, Dei Tos AP, Qi H, Giannini C, Furlanetto A, Longatti PL, et al. : Immature teratoma of the pineal gland with isochromosome 12p. Acta Neuropathol 95 : 107-110, 1998

14. de Bruin TW, Slater RM, Defferrari R, Geurts van Kessel A, Suijkerbuijk RF, Jansen $\mathrm{G}$, et al. : Isochromosome 12p-positive pineal germ cell tumor. Cancer Res 54 : 1542-1544, 1994

15. Dodgshun AJ, SantaCruz N, Hwang J, Ramkissoon SH, Malkin H, Bergthold $\mathrm{G}$, et al. : Disseminated glioneuronal tumors occurring in childhood: treatment outcomes and BRAF alterations including V600E mutation. J Neurooncol $128:$ 293-302, 2016

16. Dougherty MJ, Santi M, Brose MS, Ma C, Resnick AC, Sievert AJ, et al. : Activating mutations in BRAF characterize a spectrum of pediatric lowgrade gliomas. Neuro Oncol 12 : 621-630, 2010

17. Dubbink HJ, Atmodimedjo PN, Kros JM, French PJ, Sanson M, Idbaih A, et al. : Molecular classification of anaplastic oligodendroglioma using nextgeneration sequencing: a report of the prospective randomized EORTC Brain Tumor Group 26951 phase III trial. Neuro Oncol 18 : 388-400, 2016

18. Ellison DW, Dalton J, Kocak M, Nicholson SL, Fraga C, Neale G, et al. : Medulloblastoma: clinicopathological correlates of SHH, WNT, and nonSHH/WNT molecular subgroups. Acta Neuropathol 121 : 381-396, 2011

19. Gajjar A, Pfister SM, Taylor MD, Gilbertson RJ : Molecular insights into pediatric brain tumors have the potential to transform therapy. Clin Cancer Res 20 : 5630-5640, 2014

20. Gardiman MP, Fassan M, Orvieto E, D'Avella D, Denaro L, Calderone M, et al. : Diffuse leptomeningeal glioneuronal tumors: a new entity? Brain Pathol 20 : 361-366, 2010 
21. Gessi M, Zur Muehlen A, Lauriola L, Gardiman MP, Giangaspero F, Pietsch $\mathrm{T}$ : TP53, beta-Catenin and c-myc/N-myc status in embryonal tumours with ependymoblastic rosettes. Neuropathol Appl Neurobiol 37 : 406-413, 2011

22. Gibson P, Tong Y, Robinson G, Thompson MC, Currle DS, Eden C, et al. Subtypes of medulloblastoma have distinct developmental origins. Nature 468 : 1095-1099, 2010

23. Hasselblatt M, Gesk S, Oyen F, Rossi S, Viscardi E, Giangaspero F, et al. : Nonsense mutation and inactivation of SMARCA4 (BRG1) in an atypical teratoid/rhabdoid tumor showing retained SMARCB1 (INI1) expression. Am J Surg Pathol 35 : 933-935, 2011

24. Helfferich J, Nijmeijer R, Brouwer OF, Boon M, Fock A, Hoving EW, et al. : Neurofibromatosis type 1 associated low grade gliomas: a comparison with sporadic low grade gliomas. Crit Rev Oncol Hematol 104 : 3041, 2016

25. Hood L, Rowen L : The Human Genome Project: big science transforms biology and medicine. Genome Med 5 : 79, 2013

26. Hoshide R, Jandial R : 2016 World Health Organization classification of central nervous system tumors: an era of molecular biology. World Neurosurg 94 : 561-562, 2016

27. Jennings LJ, Arcila ME, Corless C, Kamel-Reid S, Lubin IM, Pfeifer J, et al. : Guidelines for validation of next-generation sequencing-Based oncology panels: a joint consensus recommendation of the Association for Molecular Pathology and College of American Pathologists. J Mol Diagn 19 : 341-365, 2017

28. Johnson A, Severson E, Gay L, Vergilio JA, Elvin J, Suh J, et al. : Comprehensive genomic profiling of 282 pediatric low- and high-grade gliomas reveals genomic drivers, tumor mutational burden, and hypermutation signatures. Oncologist 22 : 1478-1490, 2017

29. Joyon N, Tauziède-Espariat A, Alentorn A, Giry M, Castel D, Capelle L, et al. : K27M mutation in H3F3A in ganglioglioma grade I with spontaneous malignant transformation extends the histopathological spectrum of the histone $\mathrm{H} 3$ oncogenic pathway. Neuropathol Appl Neurobiol 43 : 271-276, 2017

30. Kallappagoudar S, Yadav RK, Lowe BR, Partridge JF : Histone H3 mutations--a special role for H3.3 in tumorigenesis? Chromosoma 124 : 177189, 2015

31. Karajannis MA, Legault G, Fisher MJ, Milla SS, Cohen KJ, Wisoff JH, et al. : Phase II study of sorafenib in children with recurrent or progressive low-grade astrocytomas. Neuro Oncol 16 : 1408-1416, 2014

32. Keedy VL, Temin S, Somerfield MR, Beasley MB, Johnson DH, McShane LM, et al. : American Society of Clinical Oncology provisional clinical opinion : epidermal growth factor receptor (EGFR) Mutation testing for patients with advanced non-small-cell lung cancer considering first-line EGFR tyrosine kinase inhibitor therapy. J Clin Oncol 29 : 2121-2127, 2011

33. Khuong-Quang DA, Buczkowicz P, Rakopoulos P, Liu XY, Fontebasso $A M$, Bouffet $E$, et al. : K27M mutation in histone H3.3 defines clinically and biologically distinct subgroups of pediatric diffuse intrinsic pontine gliomas. Acta Neuropathol 124 : 439-447, 2012

34. Kim J, Park WY, Kim NKD, Jang SJ, Chun SM, Sung CO, et al. : Good lab- oratory standards for clinical next-generation sequencing cancer panel tests. J Pathol Transl Med 51 : 191-204, 2017

35. Kleinman CL, Gerges N, Papillon-Cavanagh S, Sin-Chan P, Pramatarova A, Quang DA, et al. : Fusion of TTYH1 with the C19MC microRNA cluster drives expression of a brain-specific DNMT3B isoform in the embryonal brain tumor ETMR. Nat Genet 46 : 39-44, 2014

36. Kline CN, Joseph NM, Grenert JP, van Ziffle J, Talevich E, Onodera C, et al. : Targeted next-generation sequencing of pediatric neuro-oncology patients improves diagnosis, identifies pathogenic germline mutations, and directs targeted therapy. Neuro Oncol 19 : 699-709, 2017

37. Korshunov A, Sturm D, Ryzhova M, Hovestadt V, Gessi M, Jones DT, et al. : Embryonal tumor with abundant neuropil and true rosettes (ETANTR), ependymoblastoma, and medulloepithelioma share molecular similarity and comprise a single clinicopathological entity. Acta Neuropathol 128 : 279-289, 2014

38. Louis DN, Perry A, Reifenberger $G$, von Deimling A, Figarella-Branger D, Cavenee WK, et al. : The 2016 World Health Organization classification of tumors of the central nervous system: a summary. Acta Neuropathol $131: 803-820,2016$

39. Masui K, Mischel PS, Reifenberger $G$ : Molecular classification of gliomas. Handb Clin Neurol 134 : 97-120, 2016

40. Metzker ML : Sequencing technologies - the next generation. Nat Rev Genet $11: 31-46,2010$

41. Mostert M, Rosenberg C, Stoop H, Schuyer M, Timmer A, Oosterhuis W, et al. : Comparative genomic and in situ hybridization of germ cell tumors of the infantile testis. Lab Invest 80 : 1055-1064, 2000

42. Movassaghi M, Shabihkhani M, Hojat SA, Williams RR, Chung LK, Im K, et al. : Early experience with formalin-fixed paraffin-embedded (FFPE) based commercial clinical genomic profiling of gliomas-robust and informative with caveats. Exp Mol Pathol 103 : 87-93, 2017

43. Nambirajan A, Malgulwar PB, Sharma MC, Singh A, Pathak P, Satyarthee $G D$, et al. : C11orf95-RELA fusion present in a primary intracranial extraaxial ependymoma: report of a case with literature review. Neuropathology 36 : 490-495, 2016

44. Nikbakht H, Panditharatna E, Mikael LG, Li R, Gayden T, Osmond M, et al. : Spatial and temporal homogeneity of driver mutations in diffuse intrinsic pontine glioma. Nat Commun 7 : 11185, 2016

45. Nikiforova MN, Wald Al, Melan MA, Roy S, Zhong S, Hamilton RL, et al. : Targeted next-generation sequencing panel (GlioSeq) provides comprehensive genetic profiling of central nervous system tumors. Neuro Oncol $18: 379-387,2016$

46. Nobusawa S, Hirato J, Yokoo H : Molecular genetics of ependymomas and pediatric diffuse gliomas : a short review. Brain Tumor Pathol 31 : 229-233, 2014.

47. Nobusawa S, Orimo K, Horiguchi K, Ikota H, Yokoo H, Hirato J, et al. : Embryonal tumor with abundant neuropil and true rosettes with only one structure suggestive of an ependymoblastic rosette. Pathol Int 64 : 472-477, 2014

48. Northcott PA, Buchhalter I, Morrissy AS, Hovestadt V, Weischenfeldt J, Ehrenberger $\mathrm{T}$, et al. : The whole-genome landscape of medulloblastoma subtypes. Nature $547:$ 311-317, 2017 
49. Okada Y, Nishikawa R, Matsutani M, Louis DN : Hypomethylated X chromosome gain and rare isochromosome $12 p$ in diverse intracranial germ cell tumors. J Neuropathol Exp Neurol 61 : 531-538, 2002

50. Pajtler KW, Witt H, Sill M, Jones DT, Hovestadt V, Kratochwil F, et al. : Molecular classification of ependymal tumors across all CNS compartments, histopathological grades, and age groups. Cancer Cell 27 : 728-743, 2015

51. Parker M, Mohankumar KM, Punchihewa C, Weinlich R, Dalton JD, Li Y, et al. : C11orf95-RELA fusions drive oncogenic NF-KB signalling in ependymoma. Nature 506 : 451-455, 2014

52. Parsons DW, Jones S, Zhang $X$, Lin JC, Leary RJ, Angenendt $P$, et al. : An integrated genomic analysis of human glioblastoma multiforme. Science 321 : 1807-1812, 2008

53. Pietsch T, Haberler $\mathrm{C}$ : Update on the integrated histopathological and genetic classification of medulloblastoma - a practical diagnostic guideline. Clin Neuropathol 35 : 344-352, 2016

54. Poulos C, Cheng L, Zhang S, Gersell DJ, Ulbright TM : Analysis of ovarian teratomas for isochromosome 12p: evidence supporting a dual histogenetic pathway for teratomatous elements. Mod Pathol 19 : 766-771, 2006

55. Qaddoumi I, Orisme W, Wen J, Santiago T, Gupta K, Dalton JD, et al. : Genetic alterations in uncommon low-grade neuroepithelial tumors: BRAF, FGFR1, and MYB mutations occur at high frequency and align with morphology. Acta Neuropathol 131 : 833-845, 2016

56. Ramkissoon SH, Bandopadhayay P, Hwang J, Ramkissoon LA, Greenwald NF, Schumacher SE, et al. : Clinical targeted exome-based sequencing in combination with genome-wide copy number profiling: precision medicine analysis of 203 pediatric brain tumors. Neuro Oncol 19 : 986-996, 2017

57. Rickert CH, Simon R, Bergmann M, Dockhorn-Dworniczak B, Paulus W : Comparative genomic hybridization in pineal germ cell tumors. J Neuropathol Exp Neurol 59 : 815-821, 2000

58. Roth JJ, Santi M, Pollock AN, Harding BN, Rorke-Adams LB, Tooke LS, et al. : Chromosome band 7q34 deletions resulting in KIAA1549-BRAF and FAM131B-BRAF fusions in pediatric low-grade gliomas. Brain Pathol $25: 182-192,2015$

59. Sahm F, Schrimpf D, Jones DT, Meyer J, Kratz A, Reuss D, et al. : Nextgeneration sequencing in routine brain tumor diagnostics enables an integrated diagnosis and identifies actionable targets. Acta Neuropathol 131 : 903-910, 2016

60. Schindler G, Capper D, Meyer J, Janzarik W, Omran H, Herold-Mende C, et al. : Analysis of BRAF V600E mutation in 1,320 nervous system tumors reveals high mutation frequencies in pleomorphic xanthoastrocytoma, ganglioglioma and extra-cerebellar pilocytic astrocytoma. Acta Neuropathol $121: 397-405,2011$

61. Schneider DT, Schuster AE, Fritsch MK, Calaminus G, Harms D, Göbel U, et al. : Genetic analysis of childhood germ cell tumors with comparative genomic hybridization. Klin Padiatr 213 : 204-211, 2001

62. Schneider DT, Zahn S, Sievers S, Alemazkour K, Reifenberger G, Wiestler $O D$, et al. : Molecular genetic analysis of central nervous system germ cell tumors with comparative genomic hybridization. Mod Pathol 19 : 864-873, 2006
63. Schulte SL, Waha A, Steiger B, Denkhaus D, Dörner E, Calaminus G, et al. : CNS germinomas are characterized by global demethylation, chromosomal instability and mutational activation of the Kit-, Ras/Raf/Erk- and Akt-pathways. Oncotarget 7 : 55026-55042, 2016

64. Schwartzentruber J, Korshunov A, Liu XY, Jones DT, Pfaff E, Jacob K, et al. : Driver mutations in histone $\mathrm{H} 3.3$ and chromatin remodelling genes in paediatric glioblastoma. Nature 482 : 226-231, 2012

65. Schweizer Y, Meszaros Z, Jones DTW, Koelsche C, Boudalil M, Fiesel P, et al. : Molecular transition of an adult low-grade brain tumor to an atypical teratoid/rhabdoid tumor over a time-course of 14 years. J Neuropathol Exp Neurol 76 : 655-664, 2017

66. Silver SA, Wiley JM, Perlman EJ : DNA ploidy analysis of pediatric germ cell tumors. Mod Pathol 7 : 951-956, 1994

67. Soda M, Choi YL, Enomoto M, Takada S, Yamashita Y, Ishikawa S, et al. : Identification of the transforming EML4-ALK fusion gene in non-smallcell lung cancer. Nature 448 : 561-566, 2007

68. Solomon DA, Wood MD, Tihan T, Bollen AW, Gupta N, Phillips JJ, et al. : Diffuse midline gliomas with histone H3-K27M mutation: a series of 47 cases assessing the spectrum of morphologic variation and associated genetic alterations. Brain Pathol 26 : 569-580, 2016

69. Spence T, Perotti C, Sin-Chan P, Picard D, Wu W, Singh A, et al. : A novel C19MC amplified cell line links Lin28/let-7 to mTOR signaling in embryonal tumor with multilayered rosettes. Neuro Oncol 16 : 62-71, 2014

70. Sturm D, Orr BA, Toprak UH, Hovestadt V, Jones DTW, Capper D, et al. : New brain tumor entities emerge from molecular classification of CNSPNETs. Cell 164 : 1060-1072, 2016

71. Sturm D, Witt $H$, Hovestadt V, Khuong-Quang DA, Jones DT, Konermann C, et al. : Hotspot mutations in H3F3A and IDH1 define distinct epigenetic and biological subgroups of glioblastoma. Cancer Cell 22 : 425-437, 2012

72. Taylor MD, Northcott PA, Korshunov A, Remke M, Cho YJ, Clifford SC, et al. : Molecular subgroups of medulloblastoma: the current consensus.

Acta Neuropathol $123:$ 465-472, 2012

73. Tomić TT, Olausson J, Wilzén A, Sabel M, Truvé K, Sjögren H, et al. : A new GTF2I-BRAF fusion mediating MAPK pathway activation in pilocytic astrocytoma. PLoS One 12 : e0175638, 2017

74. Trabelsi S, Chabchoub I, Ksira I, Karmeni N, Mama N, Kanoun S, et al. : Molecular diagnostic and prognostic subtyping of gliomas in tunisian population. Mol Neurobiol 54 : 2381-2394, 2017

75. Wong SQ, Li J, Tan AY, Vedururu R, Pang JM, Do H, et al. : Sequence artefacts in a prospective series of formalin-fixed tumours tested for mutations in hotspot regions by massively parallel sequencing. BMC Med Genomics 7 : 23, 2014

76. Wu G, Broniscer A, McEachron TA, Lu C, Paugh BS, Becksfort J, et al. : Somatic histone $\mathrm{H} 3$ alterations in pediatric diffuse intrinsic pontine gliomas and non-brainstem glioblastomas. Nat Genet 44 : 251-253, 2012

77. Wu J, Armstrong TS, Gilbert MR : Biology and management of ependymomas. Neuro Oncol 18 : 902-913, 2016

78. Yu IT, Griffin CA, Phillips PC, Strauss LC, Perlman EJ : Numerical sex chromosomal abnormalities in pineal teratomas by cytogenetic analysis and fluorescence in situ hybridization. Lab Invest 72 : 419-423, 1995 
79. Zacher A, Kaulich K, Stepanow S, Wolter M, Kohrer K, Felsberg J, et al. : Molecular diagnostics of gliomas using next generation sequencing of a glioma-tailored gene panel. Brain Pathol 27 : 146-159, 2017

80. Zhang C, Berney DM, Hirsch MS, Cheng L, Ulbright TM : Evidence supporting the existence of benign teratomas of the postpubertal testis: a clinical, histopathologic, and molecular genetic analysis of 25 cases. Am J Surg Pathol 37 : 827-835, 2013
81. Zhang J, Wu G, Miller CP, Tatevossian RG, Dalton JD, Tang B, et al. : Wholegenome sequencing identifies genetic alterations in pediatric low-grade gliomas. Nat Genet 45 : 602-612, 2013

82. Zhukova N, Ramaswamy V, Remke M, Pfaff E, Shih DJ, Martin DC, et al. : Subgroup-specific prognostic implications of TP53 mutation in medulloblastoma. J Clin Oncol 31 : 2927-2935, 2013 